\title{
Effect of Annealing Temperature on Prepared Nanoparticles Li-Ferrite Using Positron Annihilation Lifetime Technique
}

\author{
A. M. Samy*, E. Hassan Aly \\ Physics Department, Faculty of Science, Ain Shams University, Cairo, Egypt \\ Email: *amany hegazy@sci.asu.edu.eg
}

Received 7 April 2015; accepted 19 May 2015; published 22 May 2015

Copyright (C) 2015 by authors and Scientific Research Publishing Inc.

This work is licensed under the Creative Commons Attribution International License (CC BY). http://creativecommons.org/licenses/by/4.0/

(c) (i) Open Access

\begin{abstract}
Lithium ferrite nanoparticles were synthesized by a sol-gel auto-combustion method. For prepared samples, the nanograins were increased with increasing the annealing temperature. Positron annihilation lifetime spectroscopy (PALS) was used to study defects at different sites for nanograins Li-ferrites. The analysis of the PAL spectrum indicated two lifetime components $\tau_{1}$ and $\tau_{2}$ for the annihilation of the positrons, and their corresponding relative intensities $I_{1} \%$ and $I_{2} \%$. For nanoparticles Li-ferrite there are correlations between: 1) $I_{2}, \tau_{2}$, annealing temperature and the total porosity $\left(P_{t}\right)$ with the grain size; 2$) I_{1}, \mu_{i}, M_{s}$ and the homogeneity with grain size.
\end{abstract}

\section{Keywords}

Nano Li-Ferrite, Porosity, Positron Annihilation, Initial Permeability, Magnetization

\section{Introduction}

Magnetic behavior of nanoparticles substance can be different from bulk due to the nano size and surface effects. Low magneto-crystalline anisotropy for bulk lithium ferrite is important in the construction of many electromagnetic devices and microwaves [1]-[3]. For magnetic nanoparticles, the effective anisotropy $\left(K_{\mathrm{eff}}\right)$ is determined by the contribution of the magneto-crystalline anisotropy, and the anisotropy resulting from interparticles interactions [4]-[6].

For single domain below a critical size, magnetic nanoparticles ferrite depends mainly on the effective magnetic anisotropy of the surface layer. Magnetically, the surface layer which is inactive for single domain inside each grain causes the decrease of saturation magnetization [7] [8]. This effect becomes less significant with in-

${ }^{*}$ Corresponding author.

How to cite this paper: Samy, A.M. and Aly, E.H. (2015) Effect of Annealing Temperature on Prepared Nanoparticles Li-Ferrite Using Positron Annihilation Lifetime Technique. Materials Sciences and Applications, 6, $436-444$.

http://dx.doi.org/10.4236/msa.2015.65047 
creasing the size of grains [9]. A single barrier model is explained the magnetic behavior for nanoparticles. Single domain nanoparticles show super-paramagnetic behavior above a certain temperature called blocking temperature $\left(T_{B}\right)$. In this state, the thermal energy $\left(K_{B} T\right)$ can overcome energy barrier $(\Delta E)$. This allows flipping of single spins from the easy direction of magnetization [10].

Magnetic nanoparticles are used in magnetic tapes, flopping discs and thin film magnetic recording media that contain nanograins [11]. If these grains were strongly interacting, then it could be difficult to change the state of one bit without also altering that of its neighbor. Magnetic nanoparticles are used in biomedical applications such as hyperthermic cancer treatment [4]. The properties of ferrite are strongly depending on sintering temperature, time [12] [13], type of substitution, its amount [14]-[16] and particle size [17]. It is reported that the particle size increasing linearly with sintering time due to enhancing the coalescence process [9]. The size of the particles also increases linearly with sintering temperature due to the decrease of lattice defects and strains. It also causes coalescence of crystallites [18]. So, the main idea in this work is to investigate the defects concentration inside nanoparticles grains, and at the grain boundaries of Li-ferrite that anneal at different temperatures [19] by using the positron annihilation lifetime spectroscopy (PALS) as a good tool to identify the defects inside and outside the grains of the sample. There are different correlations between $I_{1}, I_{2}$, and the coercivity $\left(H_{c}\right)$ for single domain and multi domains.

Due to the sensitivity of positrons towards local electron density changes, PALS is useful for studying open defects of condensed matters including high- $T_{C}$ superconductors, semiconductors [20], alloys [21] and ferrites [22]-[24]. A positron implanted in this type of materials can have different lifetimes depending on the electron density at the annihilation site. Thus, positron lifetime spectroscopy can give information about the size, type and relative concentration of various defects. By using positron annihilation spectroscopy (PAS), it is possible to obtain meaningful characteristic of inter and intra pores (nanoscal defects) distribution for nano-crystalline Liferrite. These defects play a dominant role in the physical properties of ferrites.

\section{Experimental Techniques}

Nanoparticles spinel lithium ferrites with the chemical formula $\mathrm{Li}_{0.5} \mathrm{Fe}_{2.5} \mathrm{O}_{4}$ were synthesized with a sol-gel auto combustion method. The stoichiometricl metal nitrates of $\mathrm{LiNO}_{3}$ and ferric nitrate $\left(\mathrm{Fe}\left(\mathrm{NO}_{3}\right)_{3} \cdot 9 \mathrm{H}_{2} \mathrm{O}\right)$, were dissolved in de-ionized water with addition of citric acid $\left(\mathrm{C}_{6} \mathrm{O}_{7} \mathrm{H}_{8}\right)$ and then ammonia $\left(\mathrm{NH}_{3}\right)$. By heating $\left(70^{\circ} \mathrm{C}-\right.$ $85^{\circ} \mathrm{C}$ ) and after evaporation, the gel is formed. Nano Li-ferrite samples are formed after completing the chemical reaction samples. The investigated samples in this work are the prepared Li-ferrite sample and the annealed Liferrite samples at different temperature $\left(T_{a}=673^{\circ} \mathrm{K}, 873^{\circ} \mathrm{K}\right.$ and $\left.1073^{\circ} \mathrm{K}\right)$ at heating rate of $10^{\circ} \mathrm{C} / \mathrm{min}$ for $1 \mathrm{~h}$ at atmospheric pressure. The flow chart of the preparation method is reported in Ref. [19].

By using X-ray diffraction with $\mathrm{CuK}_{\alpha}$ radiation of $\lambda=1.54056 \AA$ at room temperature, the average lattice parameters were calculated for all nano ferrite samples. Using Debye-Scherrer formula, $D=(K \lambda) /(\beta \cdot \cos \theta)$, the crystal size is calculated at each (hkl) for each sample. $K$ is a constant (0.9), $\beta$ is the full width at each half maximum, and $\theta$ is the corresponding diffraction angle [25]. The porosity percentage was calculated using Archimedes’ principle [19].

A standard fast-fast coincidence spectrometer was used for measuring positron annihilation lifetime spectra. PAL measurements were carried out at room temperature. The positron source used in this investigation was 11 $\mu \mathrm{Ci}$ of ${ }^{22} \mathrm{Na}$ deposited on a thin kapton foils (thickness $<1 \mathrm{mg} / \mathrm{cm}^{2}$ ) with a small active diameter of $\mathrm{l}-2 \mathrm{~mm}$ and sandwich between two similar pieces of each sample. In this work, two identical plastic scintillator detectors fitted with Hamamatsu photomultiplier tubes [H3378-50] NO. BA0828 were used with a prompt resolution of about 250 ps (full width at half-maximum, FWHM) and a channel constant of 6.5 ps. For each sample, lifetime spectra were recorded with about $5 \times 10^{6}$ counts accumulated under the peak. Each lifetime spectrum was analyzed into two components using the computer program LT [26] with the best fit $\chi^{2}<1.1$. Analysis of PAL spectrum for all samples decomposed into two lifetime components $\tau_{1}$ and $\tau_{2}$, order of a few hundred picoseconds, which have relative intensities $I_{1}$ and $I_{2}$. The shorter-lived component $\left(\tau_{1}\right.$ and $\left.I_{1}\right)$ belonged to positrons annihilating in the matrix and dislocation loops, and longer one $\left(\tau_{2}\right.$ and $\left.I_{2}\right)$ characterizes the annihilation of positrons trapped in vacancy clusters and three-dimensional mono vacancies defects [27]. In other words, $I_{1}$ and $I_{2}$ indicate the relative number of positrons that annihilate with different annihilation processes.

At room temperature, the magnetization was measured for powder samples using vibrating sample magnetometer (VSM, EG, PARC model No. 1551 USA). The saturation magnetization $M_{s}$ was determined for each 
sample and the coercivity $H_{c}$ from the hysteresis loop [19]. The homogeneity of the samples was calculated from the variation of the initial permeability $\mu_{i}$ with temperature by calculating the slope of the linear part at a sudden decrease of the initial permeability curve with increasing temperature. The induced voltage $V_{s}$ in the secondary coil used to calculate the initial permeability using the following formula $V_{s}=K \cdot \mu_{i}$ and $K=0.4 \pi n_{p} n_{s} I_{p} A \omega / L$; where $n_{p}$ and $n_{s}$ are the number of turns of the primary and secondary coils respectively. $A$ is the cross sectional area of the sample, $\omega$ is the angular frequency and $L$ is the average path of the magnetic flux. More details for the measurements are reported in Ref. [19].

\section{Results and Discussion}

During the preparation condition the grain size of nano-particles Li-ferrite samples were affected by changing the annealing temperature. The grain size (G.S.), was increased relative to the non-annealed Li-ferrite sample (as prepared) by raising the annealing temperature up $1073 \mathrm{~K}$. Effect of annealing temperature on long lifetime component $\tau_{2}$ and $I_{2}$ which represent as measure of size and concentration of defects at the grain boundaries is shown in Figure 1.

It is observed that $\tau_{2}$ and $I_{2}$ have a reverse behavior with increasing the annealing temperature. In other words, the lifetime $\tau_{2}$ of positrons that trapped and annihilated at inter granular pores and grain boundaries thickness defect sites, decreases while its relative intensity $I_{2}$ increases indicating that the size of defects at these sites decrease and its concentration increases. This proves that the decrease of $\tau_{2}$ and increase in $I_{2}$ with increasing the nano grain size of Li-ferrite samples as shown in Figure 2.

Similar results for the reverse behavior of $I_{2}$ and $\tau_{2}$ were reported for the bulk Cu-Zn ferrite and Mn-Zn ferrite [28] [29]. Figure 3 showed that $I_{2}$ increases with the total porosity $\left(P_{t}\right)$ for grain size (G.S.) $<109 \mathrm{~nm}$, which attributed to the increase of inter granular pores at the grain boundaries and at the same time inter domain walls. This consideration came from the reported formation of single domain inside each grain of nano grain Li-ferrite with grain size $\leq 74 \mathrm{~nm}$ [30], and it agrees with that reported for Li-Ni ferrite [31]. This means that nano size single domain Li-ferrite particles exhibit unusual behavior which was not found for the bulk ferrite materials. For nano particle Li-ferrite samples, G.S. $\geq 109 \mathrm{~nm}$ single domain behavior was changed to multi domains. Meanwhile, the inter pores were distributed between the grain boundaries and the formatted multi domains (inside the domain or at the domain walls) of the nano grains Li-ferrite samples. So, this consideration accounts on the abrupt decrease of the total porosity $\left(P_{t}\right)$ at G.S. $=109 \mathrm{~nm}$. Thermodynamically, this abrupt change in the behavior from single domain to multi domains decreases the internal stress inside the grains. Furthermore, the distribution of the intra pores inside the domains may be inhomogeneous. So, with increasing the nano grain size the sample became more homogenous as some intra pores drift to the grain boundaries.

Also, this accounts on the increase of $I_{2}$ for nano grain size $>109 \mathrm{~nm}$. Accordingly, there are correlations between $I_{2}, \tau_{2}, P_{t}$ and the nano grain size for Li-ferrite samples. The increase of the homogeneity for nano Li-ferrite is conformed experimentally in this paper.

Figure 4 represents the short lifetime $\tau_{1}$ and its relative intensity $I_{1}$ which are a measure of size and concentration of defects inside the grains as a function of the grain size for the investigated Li-ferrite samples.



Figure 1. Relative intensity $I_{2}$ and the lifetime $\tau_{2}$ with the annealing temperature. 


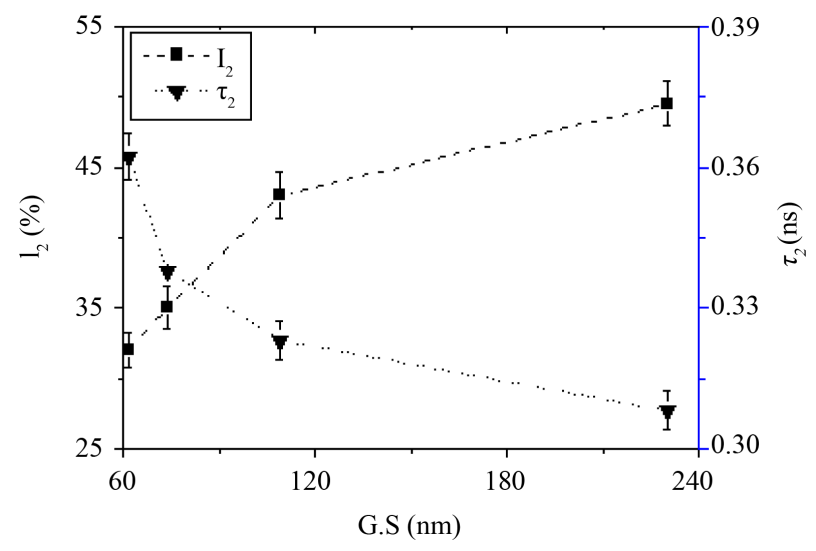

Figure 2. Relative intensity $I_{2}$ and lifetime $\tau_{2}$ with the grain size of Li-ferrite samples.



Figure 3. Total porosity $P_{t}$ and relative intensity $I_{2}$ with the grain size of Li-ferrite samples.

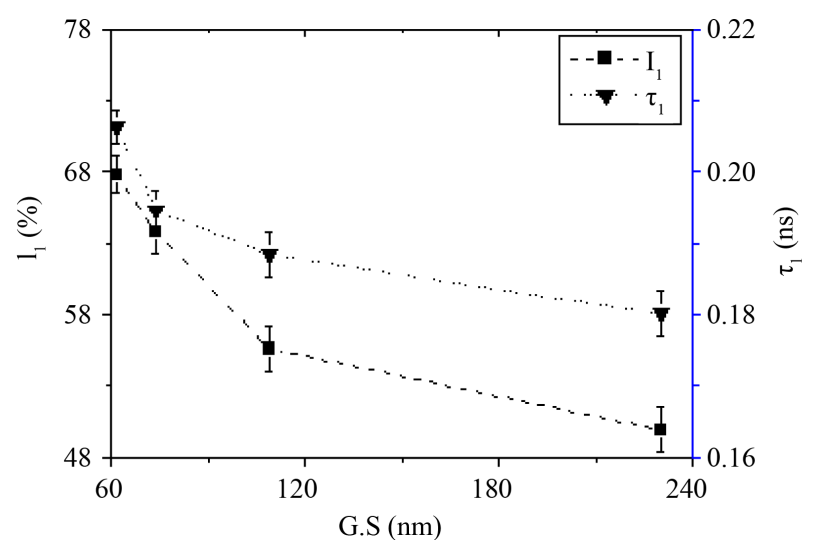

Figure 4. Relative intensity $I_{1}$ and lifetime $\tau_{1}$ with the grain size of Li-ferrite samples.

$\tau_{1}$ and $I_{1}$ decrease with increasing the grain size. The decrease of the $\tau_{1}$ is discussed as the increase of the hopping of the electrons at B-sites which causes a rapid annihilation of positrons leading to shorting lifetime $\left(\tau_{1}\right)$. Furthermore, the decrease in $I_{1}$ is attributed to the decrease of the defects concentrations (intra pores) inside the grains of Li-ferrite samples. These results agreements with that reported for bulk substituted Li-ferrites [31]. 
Accordingly, there is a correlation between $\tau_{1}$ and $I_{1}$ with the annealing temperature or the nano grain sizes for Li-ferrite substances.

Furthermore, there was a correlation between the reported saturation magnetization $\left(M_{s}\right)$ for Li-ferrite [19] and $I_{1}$ result from PAL as a nondestructive and sensitive technique to discuss the properties of the investigated nano Li-ferrites, (Figure 5).

As the concentration of defects decreases inside the grain, the magnetic super-exchange interaction increased. This accounts on the increase of the saturation magnetization with increasing the grain size. This represented other experimental explanation to the reported increase of the saturation magnetization $\left(M_{s}\right)$ with increasing the annealing temperature [19]. From another point of view, the partial ordering of $\mathrm{Li}^{1+}$ and $\mathrm{Fe}^{3+}$ ions inside the B-sites has been reported for nano Li-ferrite samples annealed up to $673 \mathrm{~K} \mathrm{[32]} \mathrm{[33].} \mathrm{Also,} \mathrm{there} \mathrm{is} \mathrm{a} \mathrm{significant}$ disordering of the oxygen network in the tetrahedral sites. This results from the abnormally high values of oxygen values displacement parameters for Li-nano ferrite sample [33]. Further increase of the annealing temperature produced full ordering of $\mathrm{Li}^{1+}$ and $\mathrm{Fe}^{3+}$ ions inside the $\mathrm{B}$-sites of the spinel lattice, and accounts on the decrease of the percentage $I_{1}$ with increasing the annealing temperature. As the occupation of A and B sites was not changed [32], then the super-exchange interaction between $\mathrm{Fe}^{3+}$ at $\mathrm{A}$ and $\mathrm{B}$ sites became stronger with increasing the annealing temperature. These two effects account on the increase of the magnetization with increasing the annealing temperature. The other important magnetic parameter for Li-ferrite is the initial permeability $\left(\mu_{i}\right)$. Figure 6 represents the value of the initial permeability that was measured at constant temperature $T=673 \mathrm{~K}$ and $I_{1}$ as a function of the grain size (G.S.) for all samples. The relative intensity $I_{1}$ and $\mu_{i}$ have reversing behavior with the increase of the nano grain size. It is reported that $\mu_{i}$ increases by decreasing the total pores for ferrites [34] [35]. According to PAL results, the increase of $\mu_{i}$ attributes to the decrease of defects concentration $\left(I_{1}\right)$ (intra pores) with increasing the grain size for all Li-ferrite samples.

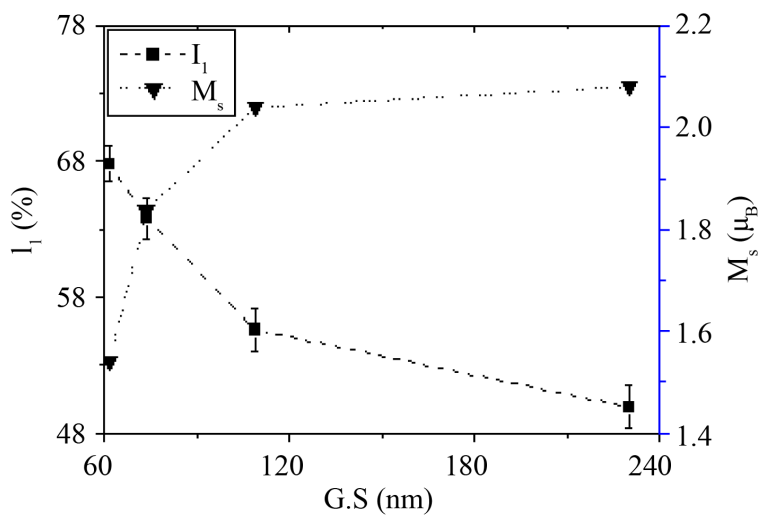

Figure 5. Relative intensity $I_{1}$ and $M_{s}$ with the grain size of Li-ferrite samples.

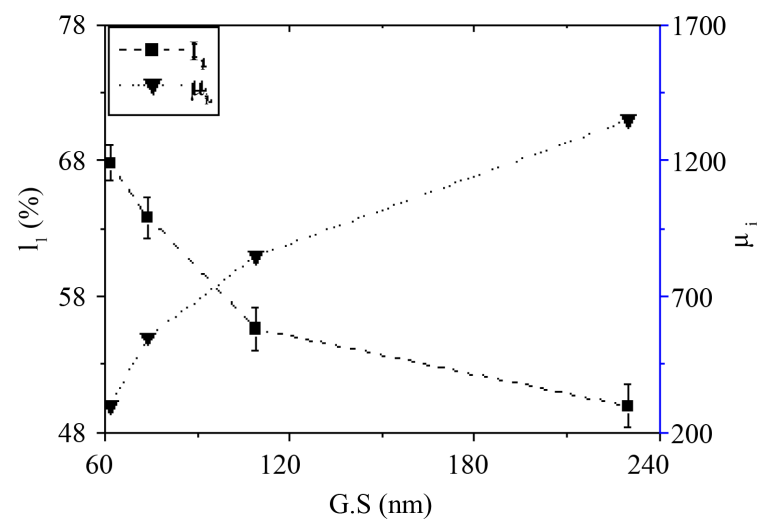

Figure 6. Relative intensity $I_{1}$ and initial permeability $\mu$ measured at $673 \mathrm{~K}$ with the grain size of Li-ferrite samples. 
Figure 7 conforms the increase of the homogeneity $\left(\Delta \mu_{i} / \Delta T\right)$ with decreasing the concentration of defects $\left(I_{1}\right)$ as a result of the increase of the grain size. This agrees with the reported increase of the degree of the (1:3) octahedral ordering of the $\mathrm{Li}^{+}$and $\mathrm{Fe}^{3+}$ ions [19] [36], i.e. increasing the distribution of these ions in the nano crystalline Li-ferrite samples. Also, this leads to increase the ordering of $\mathrm{Li}^{1+}$ and $\mathrm{Fe}^{3+}$ ions at $\mathrm{B}$-sites and leads to decrease the anisotropy. This accounts on the increase of the initial permeability with annealing temperature and the grain size. The decrease in the anisotropy with increasing the annealing temperature is reported by Agami et $a l$. [19]. This means that there are correlations between $I_{1}$, the initial permeability and the homogeneity.

Meanwhile, take into consideration the decrease of $I_{1} \%$, (Figure 7) and the increase of $I_{2} \%$, (Figure 1 ) with increasing the annealing temperature or the grain size one concludes that:

1) There is an increase of the homogeneity due to the nearly same value of $I_{1}$ and $I_{2}$ for the sample annealed at $1073 \mathrm{~K}$.

2) There are homogeneous distributions of defects inside and outside the grains; does not meant the absence of the defects.

Figure 8 shows that the coercivity $\left(H_{c}\right)$ and the relative intensity $I_{1}$ are decreased for G.S $\geq 109 \mathrm{~nm}$. This means that the dominant factor for the decrease of $H_{c}$, is the decrease of the intra granular pores. For G.S $<109$ $\mathrm{nm}, H_{c}, P_{t}$ and $I_{2}$ have the same behavior with increasing the G.S, (Figure 3 and Figure 8). So the dominant factor for the increase of $H_{c}$ for G.S $<109 \mathrm{~nm}$ is the increase of the inter granular pores, rather than considering the total pores. The increase of $H_{c}$ for G.S $<109 \mathrm{~nm}$ confirmed by the surface strain anisotropy and from inter-particle interactions [12] [14]. The abrupt change from mono domains to multi domains at G.S $=72 \mathrm{~nm}$ are affected by the type of the dominant types of pores from inter to intra granular pores type defects. Accordingly, there is a correlation between the coercivity, different types of defect concentrations $I_{1}$ and $I_{2}$. This represents a novel point; the dominant factor for the decrease of $H_{c}$ for G.S $\geq 109 \mathrm{~nm}$, is the decrease of intra granular pores of multi domains behaviors. Meanwhile, the dominant factor for the increase of $H_{c}$ for G.S $<109 \mathrm{~nm}$, is the increase of inter granular pores for single domain behavior.

\section{Conclusions}

The grain size of Li-ferrite is increased with increasing the annealing temperature relative to the non-annealed sample. With increasing the nano-grain size of Li-ferrite samples it is concluded that:

1) The concentration of defects $\left(I_{2}\right)$ at inter granular pores is increased abruptly and then slowly increased for multi-domains behavior.

2) The homogeneity of the distribution of defects inside and outside the grains became comparable.

3) The increase of the hopping of the electrons at B-sites results in shorting $\tau_{1}$ which indicates a small size of defects at intragranular pores.

4) As the concentration of defects $\left(I_{1}\right)$ at intra granular pores decreases, $M_{s}$ and $\mu_{i}$ are increased.

5) The defects concentration $I_{1}$ decreased due to the decrease of internal strain and intra pores inside the grains.

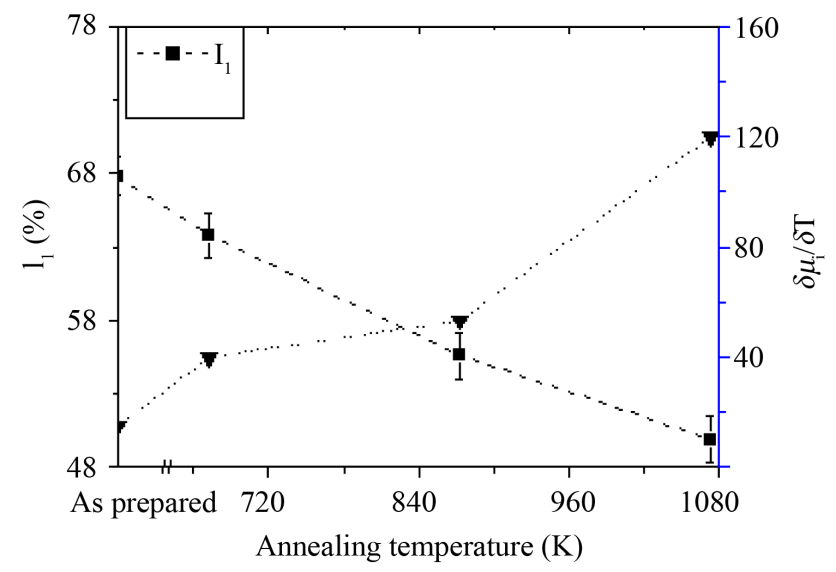

Figure 7. Relative intensity $I_{1}$ and the homogeneity $\left(\Delta \mu_{i} / \Delta T\right)$ with the annealing temperature of Li-ferrite samples. 


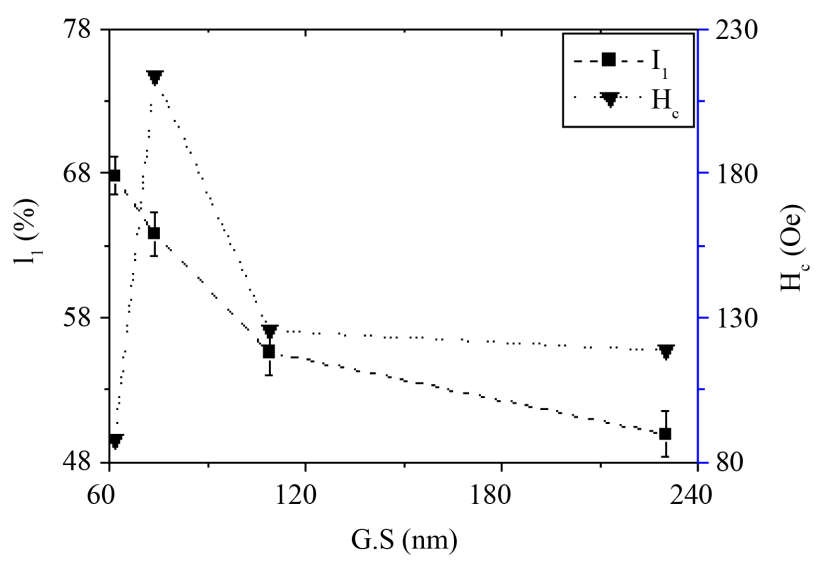

Figure 8. Relative intensity $I_{1}$ and coercivity $H_{c}$, with the grain size of Li-ferrite samples.

The novel point: the dominant factor for the decrease of $H_{c}$ for G.S. $\geq 109 \mathrm{~nm}$ is the decrease of the intra granular pores of multi domains behavior. Meanwhile, the dominant factor for the increase of $H_{c}$ for G.S. $<109 \mathrm{~nm}$ is the increase of inter granular pores for single domain nanograin Li-ferrite.

\section{Acknowledgements}

The authors would like to express their deepest thanks to Prof. Dr. A. A. Sattar, head of Magnetism Lab. Physics Dep. Faculty of Science, Ain Shams University. They are also much indebted to Prof. Reinhard Krause-Rehberg for providing the positron experiments in the Martin-Luther-University Halle-Wittenberg, Germany.

\section{References}

[1] Baba, P.D., Argentina, G.M., Courney, W.E., Dionne, G.F. and Temme, D.H. (1972) Fabrication and Properties of Microwave Lithium Ferrites. IEEE Transactions on Magnetics, 8, 83-94. http://dx.doi.org/10.1109/TMAG.1972.1067269

[2] George, M., Nair, S.S., John, A.M., Joy, P.A. and Anantharaman, M.R. (2006) Structural, Magnetic and Electric Properties of the Sol-Gel Prepar $\mathrm{Li}_{0.5} \mathrm{Fe}_{2.5} \mathrm{O}_{4}$ Fine Particles. Journal of Physics D: Applied Physics, 39, 900-910. http://dx.doi.org/10.1088/0022-3727/39/5/002

[3] Dionne, G.F. (1997) Properties of Ferrites at Low Temperatures (Invited). Journal of Applied Physics, 81, 5064-5069. http://dx.doi.org/10.1063/1.364509

[4] Majetich, S.A. and Sachan, M. (2006) Magnetostatic Interaction in Magnetic Nanoparticle Assemblies: Energy, Time and Length Scales. Journal of Physics D: Applied Physics, 39, R407-R422. http://dx.doi.org/10.1088/0022-3727/39/21/r02

[5] Yang, H., Wang, Z., Song, L., Zhao, M., Wang, J. and Luo, H. (1996) A Study on the Coercivity and Magnetic Anisotropy of the Lithium Ferrite Nanocrystallite. Journal of Physics D: Applied Physics, 29, 2574-2578. http://dx.doi.org/10.1088/0022-3727/29/10/008

[6] Goya, G.F., Berquo, T.S., Fonseca, F.C. and Morales, M.P. (2003) Static and Dynamic Magnetic Properties of Spherical Magnetic Nanoparticles. Journal of Applied Physics, 94, 3520-3528. http://dx.doi.org/10.1063/1.1599959

[7] Kodama, R.H. (1999) Magnetic Nanoparticle. Journal of Magnetism and Magnetic Materials, 200, 359-372. http://dx.doi.org/10.1016/S0304-8853(99)00347-9

[8] Batlle, X. and Labarta, A. (2002) Finite-Size Effects in Fine Particles: Magnetic and Transport Properties. Journal of Physics D: Applied Physics, 35, R15-R42. http://dx.doi.org/10.1088/0022-3727/35/6/201

[9] Shirsath, S.E., Kadam, R.H., Gaikwad, A.S., Ghasemi, A. and Morisalo, A. (2011) Effect of Sintering Temperature and the Particle Size on the Structural and Magnetic Properties of Nanocrystalline $\mathrm{Li}_{0.5} \mathrm{Fe}_{2.5} \mathrm{O}_{4}$. Journal of Magnetism and Magnetic Materials, 323, 3104-3108. http://dx.doi.org/10.1016/j.jmmm.2011.06.065

[10] Jovic, N., Antic, B., Goya, G.F. and Spasojevic, V. (2012) Magnetic Properties of Lithium Ferrite Nanoparticles with a Core/Shell Structure. Current Nanoscience, 8, 1-8. http://dx.doi.org/10.2174/157341312802884391

[11] Kechrakos, D. and Trohidou, K.N. (1998) Magnetic Properties of Dipolar Interacting Single-Domain Particles. Physical Review B, 58, 12169-12177. http://dx.doi.org/10.1103/PhysRevB.58.12169 
[12] Sahoo, S.C., Venkataramani, N., Shiva, P., Murtaza, B. and Krishnan, R. (2010) Pulse Laser Deposited Nanocrystalline Cobalt Ferrite Thin Films. Journal of Nanoscience and Nanotechnology, 10, 3112-3117. http://dx.doi.org/10.1166/jnn.2010.2173

[13] Han, Y.C., Cha, H.G., Kim, C.W., Ji, E.S., Kim, Y.H., Kang, D.I. and Kang, Y.S. (2009) The Influence of Low Temperature on Gamma-Ray Irradiated Permanent Magnets. Journal of Nanoscience and Nanotechnology, 9, 6953-6956. http://dx.doi.org/10.1166/jnn.2009.1622

[14] Zhang, Y., Fei, C., Liu, Y., Wang, R., Yan, G., Xiong, R. and Shi, J. (2010) The Effect of Surface Modification on the Magnetic Properties of $\mathrm{CoFe}_{2} \mathrm{O}_{4}$ Nano-Particles Synthesized by the Hydrothermal Method. Journal of Nanoscience and Nanotechnology, 10, 6395-6399. http://dx.doi.org/10.1166/jnn.2010.2518

[15] Rai, A. and Banerjee, M. (2008) XRD and Mössbauer Spectroscopy Investigation of Mn Substituted $\mathrm{CuFe}_{2} \mathrm{O}_{4} \mathrm{Nano}^{-}$ particles. Journal of Nanoscience and Nanotechnology, 8, 4172-4175. http://dx.doi.org/10.1166/jnn.2008.AN28

[16] Pathak, T.K., Buch, J.J.U., Trivedi, U.N., Joshi, H.H. and Modi, K.B. (2008) Infrared Spectroscopy and Elastic Properties of Nanocrystalline Mg-Mn Ferrites Prepared by Co-Precipitation Technique. Journal of Nanoscience and Nanotechnology, 8, 4181-4187. http://dx.doi.org/10.1166/jnn.2008.AN33

[17] Deka, S. and Joy, P.A. (2008) Superparamagnetic Nanocrystalline $\mathrm{ZnFe}_{2} \mathrm{O}_{4}$ with a Very High Curie Temperature. Journal of Nanoscience and Nanotechnology, 8, 3955-3958. http://dx.doi.org/10.1166/jnn.2008.201

[18] Raming, T.P., Winnubst, A.J.A., Van Kats, C.M. and Philipse, P. (2002) The Synthesis and Magnetic Properties of Nanosized Hematite $\left(\alpha-\mathrm{Fe}_{2} \mathrm{O}_{3}\right)$ Particles. Journal of Colloid and Interface Science, 249, 346-350. http://dx.doi.org/10.1006/jcis.2001.8194

[19] Agami, W.R., Ashmawy, M.A. and Sattar, A.A. (2014) Structural, IR, and Magnetic Studies of Annealed Li-Ferrite Nanoparticles. Journal of Materials Engineering and Performance, 23, 604-610. http://dx.doi.org/10.1007/s11665-013-0754-1

[20] Somoza, A. (2001) Status of Positron Annihilation Studies of Age Hardening in Aluminum Alloys. Materials Science Forum, 363-365, 9-14. http://dx.doi.org/10.4028/www.scientific.net/MSF.363-365.9

[21] Misheva, M., Djourelov, N., Margaca, F.M.A. and Miranda Salvado, I.M. (2000) Positronium Decay Study of Zirconia-Silica Sol-Gels. Journal of Non-Crystalline Solids, 272, 209-217. http://dx.doi.org/10.1016/S0022-3093(00)00153-8

[22] Hautojarvi, P., Corbel, C., Dupasquier, A. and Mills, A.P. (1995) Positron Spectroscopy of Solids. IOS Press, Amsterdam.

[23] Fradin, J., Thome, T., Grynszpan, R.I., Thome, L., Anwand, W. and Brauer, G. (2001) Precursory Stage of Damage Production in Argon Irradiated Cubic Zirconia. Nuclear Instruments and Methods in Physics Research Section B, 175-177, 516-520. http://dx.doi.org/10.1016/S0168-583X(00)00643-1

[24] Ghosh, S., Nambissan, P.M.G. and Bhattacharya, R. (2004) $\mathrm{In}^{3+}$ Substitution Effects and Defect Distribution in $\mathrm{Li}_{0.25} \mathrm{Mg}_{0.5} \mathrm{Mn}_{0.1} \mathrm{Fe}_{2.15-\chi} \mathrm{In}_{\chi} \mathrm{O}_{4}$ Studied by Positron Annihilation and Mössbauer Spectroscopy. Physica B: Condensed Matter, 353, 75-81. http://dx.doi.org/10.1016/j.physb.2004.09.003

[25] Cullity, B.D. and Stock, S.R. (2001) Elements of X-Ray Diffraction. 3rd Edition, Prentice-Hall, Inc., New York.

[26] Kansy, J. (1996) Microcomputer Program for Analysis of Positron Annihilation Lifetime Spectra. Nuclear Instruments and Methods in Physics Research Section A, 374, 235-244.

[27] Hautojarvi, P. (1979) Positrons in Solids. Springer, Berlin. http://dx.doi.org/10.1007/978-3-642-81316-0

[28] Samy, A.M., Mostafa, N. and Gomaa, E. (2006) Effect of Rare Earth Substitutions on Some Physical Properties of Mn-Zn Ferrite Studied by Positron Annihilation Lifetime Spectroscopy. Journal Applied Surface Science, 252, 33233326. http://dx.doi.org/10.1016/j.apsusc.2005.08.102

[29] Samy, A.M., Gomaa, E. and Mostafa, N. (2010) Study the Properties of Cu-Zn Ferrite Substituted with Rare Earth Ions by Positron Annihilation Analysis. The Open Ceramic Science Journal, 1, 1-4. http://dx.doi.org/10.2174/1876395201001010001

[30] Jiang, J., Yang, Y.M. and Li, L.C. (2008) Effect of Heat Treatment on the Magnetic Properties of Nanocrystalline Spinel Li-Ni Ferrite Prepared by a Simple Soft Chemistry Route. Journal of Alloys and Compounds, 464, 370-373. http://dx.doi.org/10.1016/j.jallcom.2007.09.128

[31] Aly, E.H. and Samy, A.M. (2015) A Study of Some Properties for Substituted Li-Ferrite Using Positron Annihilation Lifetime Technique. Results in Physics, 5, 80-84. http://dx.doi.org/10.1016/j.rinp.2015.03.001

[32] Jovic, N.G., Masadeh, A.S., Kremenovic, A.S., Antic, B.V., Blanusa, J.L., Cvjeticanin, N.D., Goya, G.F., Vittori, A.M. and Bozin, E.S. (2009) Effects of Thermal Annealing on Structural and Magnetic Properties of Lithium Ferrite Nanoparticles. The Journal of Physical Chemistry C, 113, 20559-20567. http://dx.doi.org/10.1021/jp907559y

[33] Jovic, N., Antic, B., Gerardo, F.G. and Spasojevic, V. (2012) Magnetic Properties of Lithium Ferrite Nanoparticles 
with a Core/Shell Structure. Current Nanoscience, 8, 651-658. http://dx.doi.org/10.2174/157341312802884391

[34] El-sayed, M.H., Samy, A.M. and Sattar, A.A. (2004) Infra-Red and Magnetic Studies of Nb-Doped Li-Ferrites. Physica Status Solidi (A), 201, 1-7. http://dx.doi.org/10.1002/pssa.200406818

[35] Samy, A.M. (2011) Magnetic and Electrical Studies of V, Cd and Gd Ions Substituted Li-Ferrite. Journal of Materials Science and Engineering with Advanced technology, 4, 133-147. http://scientificadvances.co.in

[36] Shirsath, S.E., Kadam, R.H., Gaikwad, A.S., Ghasemi, A. and Morisako, A. (2011) Effect of Sintering Temperature and the Particle Size on the Structural and Magnetic Properties of Nanocrystalline $\mathrm{Li}_{0.5} \mathrm{Fe}_{2.5} \mathrm{O}_{4}$. Journal of Magnetism and Magnetic Materials, 323, 3104-3108. http://dx.doi.org/10.1016/j.jmmm.2011.06.065 